\title{
EL DESARROLLO COGNITIVO A TRAVÉS DEL JUEGO DRAMÁTICO
}

\author{
Javier González García* \\ Universidad de Guanajuato, México \\ jr2000x@gmail.com
}

Recibido: 13/06/2020 - Aceptado: 30/10/2020

\section{Resumen}

El juego dramático se centra en distintos modos del llamado aprendizaje multisensorial, a través de procesos como crear, explorar, jugar y aprender, mejorar el pensamiento divergente, la fluidez de ideas y la flexibilidad. En este trabajo se revisan diversas líneas de investigación que detectan y desarrollan el impacto de las artes escénicas en algunos de estos procesos. Se observa cómo se producen experiencias significativas de aprendizaje que promueven un mayor bienestar subjetivo, aumentan la conciencia estética, promueven la participación social y el compromiso cívico.

Palabras clave: Juego dramático - Desarrollo socioemocional - Procesos cognitivos - Aprendizaje.

\section{MEANINGFUL LEARNING EXPERIENCES THROUGH DRAMATIC PLAY}

\begin{abstract}
Dramatic game focuses on different modes of so-called multisensory learning, through processes such as creating, exploring, playing and learning, improving divergent thinking, fluency of ideas and flexibility. In this work, several lines of research are reviewed that detect and develop the impact of performing arts in some of these processes. It is observed how significant learning experiences are produced that promote greater subjective well-being, increase aesthetic awareness, promote social participation and civic engagement.
\end{abstract}

Keywords: Dramatic Play- Social-emotional development - Cognitive processes - Learning.

\section{Introducción}

El drama o arte dramático es una expresión artística que explora el conflicto y las contradicciones del ser humano. Suele presentarse al público en forma narrativa, a través del diálogo, la acción, la experimentación y el juego con el espacio. Mientras, el juego dramático utiliza el drama como herramienta pedagógica adecuada para estudiantes de todas las edades. Incorpora elementos propios de los cursos de formación en arte dramático para facilitar el desarrollo físico, social, emocional y cognitivo de los alumnos. Y se centra en modos de aprendizaje multisensorial y multimodal. Este discurso multimodal adquiere relevancia en los espacios educativos, ya que es ahí donde se da el mayor intercambio de palabras, gestos, posturas, imágenes, esquemas, ilustraciones, etc., en relación con un objeto determinado de estudio entre el maestro y sus alumnos. De ahí las amplias posibilidades en la aplicación del juego dramático tanto en Educación Artística como en Educación Especial, dos de las grandes "marginadas" de los planes de estudios formales.

El impacto y desarrollo del arte dramático y su capacidad para fomentar el desarrollo humano es clave, al incluirlo en el proceso educativo: "confianza en uno mismo, empatía, proceso de aprendizaje, capacidad de cooperar y colaborar, concentración y memoria" (Bamford, 2014, pp.47-48). De forma paralela, también se da un impacto del teatro en la sociedad: promueve un mayor bienestar social, desarrolla la conciencia estética, fomenta la participación en actividades sociales constructivas y el compromiso cívico.

\footnotetext{
* Profesor investigador a tiempo completo Universidad de Guanajuato. Departamento de Música y Artes Escénicas Miembro Sistema Nacional de Investigadores de México.
} 
Koestler (1964) analiza la naturaleza de la creatividad, aportando algunas pistas sobre cómo se puede utilizar el arte dramático para prender la mecha de la creatividad. Quizás el proceso dramático proporciona lo que Koestler describe como un entorno maduro para desarrollar la creatividad. Argumenta que en esas situaciones las personas experimentan un desplazamiento de la atención hacia algo que no habían advertido previamente. Situar las cosas en un nuevo contexto dramático permite elaborar nuevas conexiones; en pocas palabras, cuanto más familiarizado se está con las partes, más sorprendente será el nuevo conjunto.

\section{El juego dramático como proceso de aprendizaje}

Juego y arte dramático permiten a las personas crear y vivir un mundo de ficción. Animan a las personas a aportar sus intereses y personalidad, su "acervo cultural", mueven a la participación activa en el aprendizaje y personalizan el conocimiento (Bruner, 1962). De este modo, el arte dramático se convierte en un ejemplo de creatividad al difuminar los límites entre la vida real y la ficticia, al tiempo que favorece un rico entorno capaz de crear contextos significativos y motivadores para la comunicación y el aprendizaje (Bamford, 2014). Podría decirse que el arte dramático se basa en la capacidad humana para jugar. De ahí el concepto juego dramático. Los niños sienten un deseo natural de explorar y jugar, por lo que se puede utilizar el arte dramático para despertar su interés, atención y curiosidad (Vygotsky, 1990).

El juego dramático como proceso de aprendizaje presenta unas etapas de desarrollo, que pueden ser detectadas y analizadas a partir de acciones y conductas observables (Tabla 1). A partir de estas acciones y conductas observables, de gran utilidad para los maestros, podemos ir más lejos, y tener una referencia para ir trazando dónde se ubica parte del desarrollo social de los alumnos.

Tabla 1. Etapas en el desarrollo del juego dramático (Baldwin, 2014)

\begin{tabular}{|c|c|}
\hline Etapas & Ejemplos prácticos \\
\hline $\begin{array}{l}\text { Juego dramático } \\
\text { solitario }\end{array}$ & $\begin{array}{l}\text { Niño en la esquina del hospital que está sumergido en su propio mundo, sin } \\
\text { interés por los demás }\end{array}$ \\
\hline $\begin{array}{l}\text { Juego dramático } \\
\text { paralelo }\end{array}$ & $\begin{array}{l}\text { Niña que juega al lado de otro niño (o adulto), pareciendo que juegan a lo } \\
\text { mismo, pero en realidad no teniendo nada que ver. }\end{array}$ \\
\hline $\begin{array}{l}\text { Juego dramático en } \\
\text { parejas }\end{array}$ & $\begin{array}{l}\text { Dos niñas juegan juntas. Pueden mantener una ficción durante periodos cada } \\
\text { vez más largos. Ambas se benefician de la experiencia imaginaria y } \\
\text { compartida, se comprometen a mantenerla viva. Un adulto empático puede } \\
\text { ayudar a resolver algunos problemas. }\end{array}$ \\
\hline $\begin{array}{l}\text { Juego dramático en } \\
\text { grupos pequeños }\end{array}$ & $\begin{array}{l}\text { Un grupo de unos cuatro niños puede evolucionar y permanecer unido en una } \\
\text { única ficción, dividiéndose en grupos más pequeños si fuera necesario. Cada } \\
\text { miembro del grupo aprende que no es el único dueño de la ficción, sino que } \\
\text { tienen que compartirla con los demás. Un profesor o asistente puede servir de } \\
\text { modelo y apoyo. }\end{array}$ \\
\hline $\begin{array}{l}\text { El arte dramático } \\
\text { para toda la clase }\end{array}$ & $\begin{array}{l}\text { Sólo cuando el profesor lo prepara de antemano. Forma de juego dramático } \\
\text { muy avanzada e inclusiva, cuyo foco es el aprendizaje. La evaluación de la } \\
\text { escena pertenece a todos, el profesor construirá una estructura y un marco } \\
\text { mediante estrategias y convenciones dramáticas que pueden tener elementos } \\
\text { teatrales. }\end{array}$ \\
\hline
\end{tabular}

Sæbø (2009) analiza el valor del arte dramático como forma de aprendizaje estético. Los principales hallazgos de este estudio longitudinal, durante más de 10 años, muestran que el aprendizaje basado en el arte dramático permite a los estudiantes participar activamente en su propio proceso de aprendizaje. Los resultados muestran que el arte dramático fortalece y mejora las relaciones dentro del entorno y el proceso de aprendizaje.

Así mismo, aplicando el modelo de Gardner $(1983,1999)$ el arte y el juego dramático pueden ofrecer a las personas la oportunidad de usar diferentes combinaciones de sus múltiples inteligencias, lingüística, visual, musical, kinestésica, lógico deductiva, interpersonal, intrapersonal, o naturalista, como puntos de partida para el aprendizaje para alumnos de distintas preferencias educativas (Tabla 2): 


\begin{tabular}{|c|c|}
\hline $\begin{array}{l}\text { Inteligencia } \\
\text { desarrollada }\end{array}$ & Aportaciones concretas del juego y arte dramático \\
\hline Lingüística & $\begin{array}{l}\text { En el juego dramático el lenguaje oral surge de forma espontánea en la } \\
\text { improvisación y se prepara en una representación. El arte dramático integra la } \\
\text { palabra escrita y la hablada en un guión, y desarrolla la comprensión de un texto } \\
\text { y subtexto. }\end{array}$ \\
\hline $\begin{array}{l}\text { Lógica- } \\
\text { matemática }\end{array}$ & $\begin{array}{l}\text { La resolución de problemas es clave en el proceso dramático. En toda pieza } \\
\text { dramática tiene que haber un conflicto que los alumnos, desde sus personajes, } \\
\text { han de resolver. Presentar y actuar una escena ayuda a resolver problemas reales. }\end{array}$ \\
\hline Espacial & $\begin{array}{l}\text { El uso del espacio físico y personal entre los personajes, tanto práctica como } \\
\text { simbólicamente (en relación al significado) es importante. }\end{array}$ \\
\hline $\begin{array}{l}\text { Corporal- } \\
\text { cinestésica }\end{array}$ & $\begin{array}{l}\text { A veces, el juego dramático puede ser muy físico. Explora los efectos de contrastar } \\
\text { el movimiento con la quietud. Requiere y desarrolla un control físico del cuerpo, } \\
\text { gestos y movimientos. El teatro físico/danza y el teatro musical, demandan muchas } \\
\text { competencias físicas. }\end{array}$ \\
\hline Musical & $\begin{array}{l}\text { En el juego dramático la música es estímulo y acompañamiento para crear } \\
\text { ambiente o etiquetar una experiencia emocional auditivamente }\end{array}$ \\
\hline Interpersonal & $\begin{array}{l}\text { La interacción social, la cooperación y la capacidad de trabajar con los demás es } \\
\text { un principio básico del juego y arte dramático exitoso. Escuchar las ideas de los } \\
\text { otros con atención, calibrar las necesidades de los coparticipantes, empatizar, } \\
\text { aprender diferentes puntos de vista y responder sensiblemente a ellos es } \\
\text { fundamental en el juego dramático }\end{array}$ \\
\hline Intrapersonal & $\begin{array}{l}\text { El juego dramático ayuda a desarrollar la identidad. Es imprescindible acceder a } \\
\text { los sentimientos y emociones personales para guiar el comportamiento de un } \\
\text { personaje. }\end{array}$ \\
\hline Naturalista & Puede usarse en la creación de obras y piezas dramáticas \\
\hline Espiritual & $\begin{array}{l}\text { El drama implica e inspira reflexión y contemplación (a través del ritual) de la } \\
\text { condición e identidad humana. También esclarece situaciones reales y apoya la } \\
\text { imaginación, para sobrepasar sus límites, fomentando el crecimiento y la } \\
\text { transformación. }\end{array}$ \\
\hline
\end{tabular}

El juego dramático puede utilizarse para desarrollar estilos de enseñanza y aprendizaje. Estimula la imaginación y permite explorar experiencias y temas diversos en un entorno seguro y colaborativo.

El arte dramático, como uso, proceso y aplicación narrativos, pudiera funcionar como técnica de andamiaje $^{1}$ del aprendizaje en un segundo idioma y en la alfabetización de la lengua materna, reforzando y fortaleciendo el desarrollo de habilidades del lenguaje. El juego dramático permite a los alumnos tener cada vez más competencia, independencia y seguridad en sí mismos; abre la puerta a un nuevo tipo de aprendizaje y a la interiorización de la lengua de forma creativa y placentera (Vygotsky, 2005). Mercer (2002) sugiere que los niños pueden usar el lenguaje como una herramienta para el pensamiento crítico y creativo. Para ello se requiere: a) la participación en un diálogo meditado y razonado; b) tener compañeros de conversación como modelos de lenguaje y c) usar el lenguaje para razonar, reflexionar, cuestionar y explicar las ideas propias a los demás.

La calidad del aprendizaje de un idioma también puede cambiar con el tiempo gracias a la dramatización y al juego de roles. Quizás al principio un alumno de nivel inicial sólo alcance una comprensión receptiva de la historia. Dado que la interpretación dramática es un idioma internacional, el alumno de nivel inicial puede seguir la historia a través de lo que ve y captar intuitivamente el idioma mientras se desarrolla la acción. Además, el arte dramático permite a los estudiantes reproducir y recontar la historia. A medida que aumenta su nivel, la interpretación dramática permite a los alumnos explorar diversos temas y personalizar y transferir parte del idioma adquirido a su propia vida. El arte dramático les permite mejorar la velocidad y calidad del aprendizaje del idioma a través de procesos de imitación, repetición, gesticulación, educación de la voz y de distintas categorías de comunicación no verbal (Bamford, 2014, p.39).

Wandell y su equipo (2009) probaron a detectar diferencias cognitivas entre alumnos de artes escénicas y música, y otros sin formación específica en estas áreas. En concreto, investigaron el desempeño en una variedad de tareas de razonamiento, y si existían diferencias en los patrones de la actividad cerebral de los estudiantes. Para ello, se utilizó la técnica de Resonancia Magnética funcional (fMRI, Índice del nivel de actividad específica, en regiones del cerebro centradas en tareas concretas). La hipótesis a comprobar fue si los estudiantes de artes escénicas utilizan sus cerebros de forma diferente, para poder entonces observar diferencias en los patrones de activación cerebral. Las regiones específicas muestran un aumento en la activación del rendimiento en estudiantes de artes escénicas, mostrando una disminución de la activación en otras regiones cerebrales.

${ }^{1}$ Asesoramiento, colaboración y apoyo que se ofrece para guiar al niño hacia un nuevo tipo de aprendizaje. 
El foco de investigación fue doble. Primero determinar los tipos de cambios con base neuronal que se producen en función de la exposición a un proceso de formación en artes escénicas. El segundo fue postular los mecanismos cerebrales que podrían llevar a estas mejoras. Este segundo objetivo es particularmente importante, ya que los intentos anteriores para investigar si las artes tienen efectos sólidos en el cerebro no hallaron mecanismos neuronales específicos que pudieran estar involucrados. Por lo tanto, el objetivo de la investigación fue ir más allá de las reivindicaciones vagas y generales sobre los efectos de una formación en artes escénicas con la comprobación de hipótesis específicas.

En particular la investigación se centró en estudiar los efectos de las artes escénicas en los procesos cognitivos fundamentales implicados en el razonamiento, como la construcción narrativa y escénica, y la habilidad para trazar información de un contexto a otro muy diferente, proceso conocido como transferencia. La pregunta predominante aquí es si las habilidades que se adquieren en las artes escénicas se transferirán a otros dominios. Es decir, el objetivo fue observar si la formación en artes escénicas influye en la capacidad de razonamiento analógico (modalidad de razonamiento que consiste en obtener una conclusión a partir de premisas en las que se establece una similitud o analogía entre elementos o conjuntos de elementos distintos). Se ha investigado si los estudiantes de teatro y música razonan de forma diferente a otros estudiantes, y cuáles son los cambios basados en el cerebro que subyacen a estas diferencias.

Otra pregunta de investigación fue si los estudiantes de artes son intrínsecamente diferentes a otros estudiantes que no son de artes, abriendo la posibilidad de si estas diferencias podrían deberse a diferencias genéticas que predisponen a los estudiantes a preferir y elegir las artes escénicas en lugar de otras áreas de la educación.

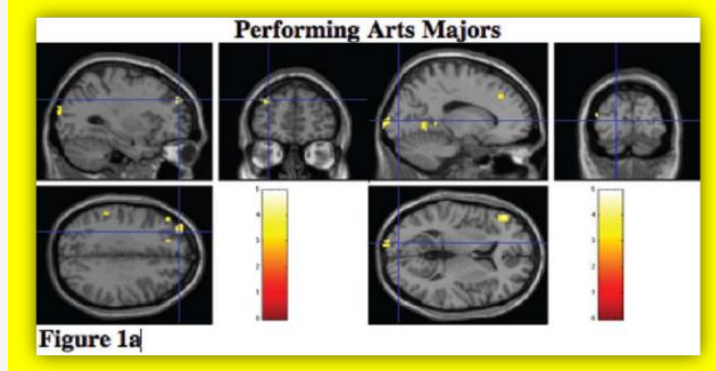

Figura 1. Diferencias cognitivas artes escénicas, música, y sin formación concreta (Wandell et al., 2009).

Los resultados apuntan a importantes diferencias entre la memoria de trabajo de los estudiantes de música y la de los otros dos grupos de estudiantes (teatro y grupos control). Además, los resultados de ADN del genotipo pueden indicar que hay diferencias genéticas entre estudiantes de artes escénicas y los estudiantes del grupo control. Se recogieron una muestra amplia de ADN para intentar determinar si estas diferencias son estadísticamente significativas. Estos resultados no mostraron diferencias entre los estudiantes y la actividad cerebral en el manejo y retención de objetos. Los datos de la fMRI no revelaron diferencias entre los estudiantes de artes y los grupos control. Sin embargo, el análisis a través de resonancia magnética funcional ha revelado unas diferencias significativas entre los estudiantes que obtuvieron una puntuación alta en una prueba de creatividad y los que obtuvieron puntajes bajos.

Se abrieron cuatro rutas de explicación. En primer lugar, se usa de forma estandarizada las tareas de comportamiento, como la retención de dígitos y la elaboración de distintas figuras. En segundo lugar, se utilizan tareas conductuales que aprovechan los procesos de razonamiento abstracto pensado para ser estimulado por una persona experta en artes escénicas (generación de acciones y de analogías a través de objetos). En tercer lugar, se realizó una neuroimagen a través de la fMRI de los estudiantes. En cuarto lugar, se realizó un análisis genético (genotipo ADN) de los diferentes grupos participantes.

En general, se encuentran algunas diferencias, tanto a nivel de comportamiento como genético. En particular, se han encontrado diferencias en la activación del hemisferio izquierdo del lóbulo frontal, que son consistentes con la hipótesis de que los estudiantes de artes son más propensos a comprometerse en la recuperación simbólica. Cuando se altera la tarea de modificar los usos de objetos durante el tercer año, no se encuentran diferencias en la activación cerebral entre los estudiantes de artes escénicas y el grupo control. Esto indica que es en el proceso de generación y uso de las ideas representadas, y no en responder a nuevas ideas, donde reside la diferencia clave entre los dos grupos. En próximos trabajos se van a analizar los datos genéticos restantes para determinar con más precisión si existen diferencias.

Catterall (2002) analizó los estudios realizados sobre los efectos del teatro en entornos escolares, e identificó muchos beneficios, algunos de ellos relacionados directamente con las materias curriculares y otros, que son los más importantes, con el desarrollo integral de la persona. Los más representativos fueron: convierte los conceptos abstractos en concretos, aborda los contenidos curriculares desde una perspectiva más atractiva, mejora su vocabulario, acerca y relaciona el aprendizaje al mundo real; permite reflexionar a los alumnos sobre lo que hacen, permite que comparen sus opiniones con las de los demás, fomenta la tolerancia y el respeto por los demás, mejora su autocontrol y autoestima, suministra un sentimiento de libertad acompañado de un sentido de responsabilidad. 


\section{La confianza en uno mismo}

Karakelle (2009) utilizó un test estándar en materia de creatividad para medir la influencia del arte dramático en la creatividad del individuo. Este es el Test de pensamiento creativo de Torrance - TTCT (1974). Los resultados revelaron que los procesos creativos pueden mejorar el pensamiento divergente, la fluidez de ideas y la flexibilidad. El pensamiento divergente es esencial para la creatividad, dado que implica pensar en múltiples direcciones, buscar cambios e investigar. La fluidez se mide por la cantidad de ideas poco asociadas y convencionales que se generan sobre un tema específico, mientras que la flexibilidad, por el número de asociaciones relacionadas con ámbitos diferentes. Gracias a su capacidad para dejar finales abiertos, el arte dramático creativo tiende a estimular el potencial creativo de las personas, aumentando su tolerancia ante la incertidumbre y provocando su curiosidad.

Asimismo, se mantiene que el proceso grupal que normalmente forma parte del arte dramático podría incrementar directamente la creatividad. Por ejemplo, los participantes en un proceso dramático tienen que ser conscientes de las diferentes respuestas de otros individuos. Al generar una dinámica social que necesita probar o asumir riesgos, la experiencia dramática anima a los participantes a «decidir ser creativos", paso indispensable para aumentar la creatividad. Aunque por supuesto se puede defender que muchas actividades aumentan la confianza en uno mismo (por ejemplo, participar en actividades deportivas, hablar en público o trabajar como voluntario), los beneficios específicos del arte dramático podrían atribuirse al modo en que consigue crear una atmósfera de seguridad, confianza y colaboración (Bamford, 2014, p.45).

En las observaciones con niños que participaban en los programas de arte dramático del Teatro Nacional de Londres mostraron que éstos ganaban confianza en sí mismos, influyendo positivamente en otras áreas de su vida; disfrutaban más en la escuela y mejoraban sus habilidades comunicativas. Este proyecto de investigación, de tres años de duración, reveló que a través del estudio del teatro los niños experimentaban «un destacado aumento de la confianza en sí mismos en el aula». Al compararlos con otros niños que asistían a centros escolares similares y no participaban en el programa de arte dramático, el estudio reveló que los alumnos del Teatro Nacional mostraban una mejora significativa en sus competencias orales (habilidad para hablar y escuchar), además de la citada confianza y seguridad en sí mismos en situaciones públicas.

\section{Empatía}

A través de las experiencias indirectas vividas con el juego dramático o dramatización, las personas pueden encontrar el sentido de su propio comportamiento y el de los demás, al tiempo que desarrollan otros aspectos de la inteligencia emocional. Para poder interpretar un papel de forma competente, un actor debe ser capaz de conseguir una empatía con el otro (Van Zweden, Bosma y Ladan, 2014). La empatía es un elemento clave dentro de los aspectos sociales y emocionales del aprendizaje. Prendiville y Toye (2007) argumentan que las actividades orales y de escucha presentes en el arte dramático permiten practicar conductas empáticas.

Una aplicación práctica de este uso del arte dramático es la que se realiza en la formación de médicos. Cada vez más, los programas universitarios y de postgrado en medicina exploran la habilidad de las artes para dilucidar la condición humana de la empatía, puesto que está relacionada con aspectos vitales de la atención al paciente. En la University of California, estudiantes y profesores de los departamentos de medicina y literatura inglesa realizaron lecturas informales de distintas escenas extraídas de obras dramáticas. Los estudiantes de medicina participaron en lecturas dramatizadas de obras de teatro que fueron grabadas y proyectadas ante un grupo de treinta estudiantes para abrir el debate. Entre los temas discutidos se trataron los diferentes modos en que los pacientes afrontaban su enfermedad y cómo los futuros médicos podrían abordar escenarios clínicos similares. El estudio reveló que los estudiantes participantes tendían a ser más empáticos con los pacientes y con otros profesionales sanitarios que los que no lo habían hecho (Bamford, 2014).

La compañía del Reino Unido Theatrescience tiene como objetivo tender lazos entre un arte escénico de calidad y las ciencias biomédicas "para explorar la relación entre las artes y las ciencias, analizando las ideas preconcebidas al respecto y sugiriendo cómo pueden cuestionarse". Además, analiza las colaboraciones entre científicos/médicos y profesionales del teatro. El informe de investigación de este proyecto llegó a las siguientes conclusiones:

"1. Existe un prejuicio persistente, de que la combinación entre ciencia y teatro genera obras de poca calidad, a pesar de que cada vez hay más pruebas que indican lo contrario; 2. La mayoría de los participantes en el programa NMF creen que la ciencia se representa de forma demasiado simplista en las artes, en caso de que aparezca representada de algún modo; 3. Tanto los científicos/profesionales sanitarios como los escritores necesitan tener cierta experiencia en teatro científico antes de poder apreciar lo que les ofrece; 4. Tanto profesionales teatrales, como científicos y público en general pueden aportar nuevas perspectivas; 5 . Es importante que los escritores tengan una buena relación con su asesor científico para poder obtener un asesoramiento experto durante el proceso de creación; 6 . La relación con un asesor científico puede ir más allá de limitarse a responder preguntas especializadas; pueden actuar como mentores y abrir camino a una información fidedigna; 7. La dirección científica y dramática no pueden estar completamente 
separadas; 8. Las colaboraciones tienden a aumentar la superposición de los papeles entre los distintos individuos" (IATL, 2013).

Tanto para los artistas como los profesionales involucrados, el proyecto aportó nuevas ideas. También demostró que cuando científicos y artistas trabajaban juntos, las ideas científicas podían divulgarse con mayor eficacia, ya que el arte dramático resulta ser un medio idóneo para transmitir ideas complejas a una comunidad más amplia. El resultado del proyecto indicó que tanto la ciencia como las artes comparten un proceso de abstracción, proceso que implica reducir los componentes fundamentales de información para conservar sus rasgos más relevantes. Las abstracciones en las artes y las ciencias se forman reduciendo el contenido de la información de un concepto o fenómeno observable a un formato más comprensible y fácil de comunicar.

\section{Cooperación y colaboración}

El trabajo en grupo que se requiere para crear montajes escénicos fomenta la cooperación y el trabajo en equipo. En el marco de una producción teatral, el proceso creativo individual queda subordinado a las intenciones y voluntad del grupo. Esta tensión de grupo que se genera en el arte dramático proporciona a los niños una oportunidad para desarrollar sus habilidades sociales y colaborativas. A través del arte dramático, las personas se relacionan entre sí y forjan grupos sociales significativos (González García 2014). La teoría sobre el Aprendizaje Cooperativo, una ramificación del Constructivismo, defiende la idea de que cuando mejor se aprende es cuando los alumnos participan activamente en el propio proceso de aprendizaje y trabajan conjuntamente para alcanzar un objetivo común (Vygotsky, 1978). A través del juego dramático las personas aprenden con mayor profundidad y complejidad, y disfrutan aún más con la experiencia.

A través del arte dramático, las personas desarrollan una conciencia del yo (mente, cuerpo y voz) y de los demás (colaboración y empatía), aumentando la comprensión del comportamiento humano: sus motivaciones, diversidad, cultura e historia. Un buen ejemplo es el proyecto "Thinking Together"2que está dirigido a mejorar el intercambio de opiniones entre niños y ayudar a profesores a procurar ese intercambio. Se incluía un contrato con normas básicas para dialogar, que se asemeja mucho al contrato dramático, encima de un escenario. El arte dramático permite a las personas reflexionar con mayor seguridad y apertura sobre temas importantes para ellos, al tiempo que les permite mantener distancia. En una producción teatral, tanto los participantes como el público conviven en una suspensión acotada del tiempo, lugar e identidad. Las habilidades y cualidades desarrolladas gracias al arte dramático, como el trabajo en equipo, la creatividad, el liderazgo y la capacidad de asumir riesgos son activos importantes en todas las disciplinas y áreas de la vida.

\section{Concentración y memoria}

A través del juego y arte dramático se puede aumentar la memoria sensorial ya que sirve no sólo para presentar personajes sino para representarlos. Esta alta capacidad de memorización se basa en recordar utilizando todos los sentidos. En la caracterización e interpretación dramática, el actor observa la vida cotidiana y combina estas observaciones de forma multisensorial para representar el recuerdo de un arquetipo social y el de una emoción. Se requiere una inmensa concentración para evocar una representación. Y no sólo los actores profesionales. Los niños pequeños tienen esta habilidad: un niño puede imitar con facilidad el enfado de su padre o la cara de sorpresa de su madre, puede representar con claridad a su profesor o reproducir una discusión con su hermano. Estas habilidades multidimensionales ponen de manifiesto tanto una gran capacidad de concentración y observación como la habilidad de evocar recuerdos y representarlos (Bamford, 2014, p.52).

El proceso de dramatización estimula la imaginación y permite a las personas explorar temas y experiencias en un entorno seguro y reconfortante. Esta representación y repetición de forma independiente permite a las personas explorar de un modo imaginativo aspectos y sentimientos que van más allá de la realidad; en otras palabras, utilizar su imaginación (Motos, 2005). La imaginación es una habilidad vital para enfrentarse a las tareas, sentimientos y problemas del día a día. Nuestra imaginación creativa es lo que nos permite acceder a las infinitas posibilidades de la creatividad en cualquier situación a la que nos enfrentamos. De este modo, los acontecimientos imaginativos que se desencadenan en el proceso de dramatización pueden ayudar a las personas a enfrentarse a situaciones emocionales complejas, permitiéndoles adquirir práctica en un contexto seguro y sin riesgos para poder explorar situaciones complejas.

\section{Conciencia estética}

El teatro tiene una larga historia. En sus orígenes, se trataba de embellecer una buena historia utilizando una gama de dispositivos dramáticos. Las artes escénicas adoptan diversas formas como la pantomima, el clown, las obras dramáticas, los cuentacuentos, las novelas radiofónicas, la danza teatro, los melodramas, los títeres, las improvisaciones, el teatro de máscaras, la oratoria, la dramaturgia, o la dirección y producción.

Desde la antigüedad, las artes escénicas se han utilizado para educar a la sociedad. Las personas aprenden a través de la estética de la experiencia dramática. Y, sin embargo, la opinión popular sobre una

${ }^{2}$ Consultar en www.thinkingtogether.educ.cam.ac.uk. 
obra depende, generalmente, de sus experiencias anteriores y de las expectativas que se aplican posteriormente a nuevas situaciones. Cuanto más teatro vean y experimenten las personas, mejor podrán extraer el sentido de sus experiencias teatrales (Bamford, 2014).

Los estudiantes que acuden a los teatros desde pequeños, se sentirán más cómodos con el teatro en la escuela. Unas experiencias teatrales ricas cuentan con más probabilidades de captar la atención y suscitar conversaciones y preguntas (Franks, 2007). Una actividad dramática eficaz debe presentar un tema complejo, apto para ser analizado y debatido en profundidad y que afecte diversas áreas de estudio, entre ellas la estética, la historia, la ética, la gestión. Estos temas mejoran la comprensión cultural al ampliar nuestras perspectivas y, con frecuencia, retratan la vida desde diferentes puntos de vista, culturas y épocas.

\section{Participación en actividades sociales y compromiso cívico}

El compromiso cívico es un comportamiento público y generalmente colectivo. Cuando la escena está orientada a este compromiso, su propósito principal puede ser el de abordar distintos temas sociales. Por ejemplo, la iniciativa -Theatre Without Borders- Teatro sin fronteras es un movimiento internacional basado en el teatro que busca un impacto para contribuir a la construcción de la paz. ImpactArts utiliza las artes visuales, la música, el arte dramático, la danza y la tecnología para trabajar en comunidades locales con personas de todas las edades. Esta organización utiliza el arte dramático como una herramienta para conseguir un cambio, mejorar el entorno y ayudar a las personas a reincorporarse a la vida laboral o mejorar su calidad de vida. Del mismo modo, el Open Clasp Theatre colabora con la Comisión de Derechos Humanos e Igualdad del Reino Unido en temas relacionados con la equidad y la integración. A pesar de centrarse en la actividad teatral, la compañía colabora con profesionales del mundo sanitario, de servicios sociales y del sistema judicial, con distintas asociaciones de la comunidad y con el público en general. Se centran en las experiencias de mujeres y jóvenes dedicadas a la prostitución o víctimas de explotación sexual; mujeres que han tenido que dar a sus hijos en adopción (debido a retirada de la custodia por situaciones de violencia doméstica o drogadicción); mujeres sin techo, con problemas de salud mental y minorías sexuales, entre otras.

De forma paradójica, las actividades escolares que implican movimiento, ya sean artísticas como cualquier estilo de baile, de movimientos en escena en el juego dramático, o deportivas como en el caso de la Educación Física, están siendo reducidas en el sistema escolar. Sin embargo, las investigaciones en neurociencia están demostrando su importancia a todos los niveles, incluido el cognitivo. Por ejemplo, la danza es una forma adecuada para desarrollar tres aspectos del pensamiento creativo: fluidez, originalidad y capacidad de abstracción (Bradley, 2002). Hoy sabemos que los mismos circuitos neuronales que se activan al realizar una acción también lo hacen al observar a otra persona haciéndola. Estas neuronas espejo posibilitan la imitación, una poderosa forma de aprendizaje. La neurociencia supone que estas neuronas desempeñan una función importante dentro de las capacidades cognitivas ligadas a la vida social, como la empatía y la imitación. Pero, ¿qué son y qué implican las neuronas espejo a nivel escénico?

\section{Neuronas espejo}

Para Brook (2002) el teatro es como una puerta que abre la posibilidad de que estén en la misma sintonía todos los participantes, conectando a actores, creadores, espectadores, y de esta forma estimular la imaginación y la cognición de cada uno de ellos, consiguiendo que todos sean a la vez creadores y observadores.

El arte en general y el teatro en concreto, tiene el poder de estimular las emociones, favoreciendo la adquisición del lenguaje. El niño consigue configurar su lenguaje a través de la conciencia corporal, la imagen y la percepción de sí mismo.

A través del arte, el niño logra adquirir la concepción de sí mismo de forma plena. A través del teatro el niño se sumerge en su experiencia artística, concibe su propio cuerpo en su absoluta totalidad, no discierne su dificultad de expresión verbal como estamos acostumbrados a ver en terapias tradicionales.

Y va a ser mediante la dramatización, cómo el niño vivencia su propia imagen corporal, y así, de forma inconsciente, activa diferentes áreas sensoriales implicadas en el desarrollo del lenguaje, es decir se genera un poder curativo. El arte es el hilo conductor entre la realidad y la emoción. Tiene ese poder de estimulación, lográndolo simultáneamente en multitud de órganos y terminales neuronales que estimulan, a su vez, al propio lenguaje.

Desde la experiencia artística y estética, el niño adquiere la "sensación de sí mismo" que Damasio (2011) definía como las "huellas fisiológicas que la experiencia deposita en el cuerpo". Las neuronas responden a los estímulos que percibimos, por lo tanto, el arte, y su extraordinario poder de estimulación, es capaz de provocar dichos estímulos de forma significativa "conformando circuitos neuronales especializados y patrones de actividad que representamos mentalmente" (Luna, 2008, p.16).

La práctica escénica activa el sistema sensoriomotriz, una variedad de estímulos son retenidos por las neuronas sensoriales para transformarlos en señales eléctricas y químicas (proceso de transducción). Las neuronas responden de diferente manera a los estímulos naturales y a los estímulos emocionales significativos. Estos últimos son desencadenados por la interpretación artística y son detectados antes incluso que la atención selectiva. Con las descargas de emociones, se producen respuestas químicas que modifican distintas funciones de las vísceras, los órganos y el sistema nervioso central. Estos circuitos neuronales implicados en la emoción, organizan y modifican el control de la "función cardiovascular y respiratoria siendo responsable de la función del control de los movimientos de la laringe, la lengua, la cara 
y la faringe, en el que la plasticidad cerebral permite asumir nuevas funciones para perfeccionar sus partes" (Luna, 2008, p. 24).

No podemos desvincular la emoción de los procesos cognitivos, motores y sensoriales implicados en el lenguaje. Para asimilar de forma correcta el lenguaje, se precisa del estímulo que proviene del entorno. La mejor manera para captar la atención es mediante canales implícitos, como la emoción y el movimiento. Se trata de recibir información. Cuantos más sentidos se encuentren implicados los procesos de expresión y comprensión del lenguaje, más información será recibida y más sencillo será su almacenamiento. Al incorporar el movimiento en el proceso de adquisición del lenguaje, aumenta la probabilidad de que esa información que se transmite sea recibida y asimilada. El aprendizaje Kinestésico contribuye a la retención de la información, a su recuerdo, a su procesamiento y a su transmisión posterior. Se trata de un aprendizaje significativo (Luna, 2008, p.43).

\section{¿Puede hablarse de arte-terapia o se debería afirmar que todo arte es terapia?}

La actividad artística y la experiencia estética constituyen además una vía terapéutica, frente a alteraciones de la comunicación. El arte como terapia busca indagar en el conocimiento interno del ser humano a través de las emociones estéticas y su expresión, especialmente cuando el ejercicio de la palabra no basta o no es suficiente. En arteterapia, el proceso se impone al resultado final. El arte es un camino desconocido como proceso dramático que se destruye y renueva sin cesar (López y Martínez, 2006, pp. 13-14).

Es un error creer que existen algunos teatros-laboratorios. Todos los teatros son laboratorios: en todos se experimenta algo que no es real, pero que es en vista de la denominada realidad (Cruciani, 1995, p. 92).

Sofía et al. (2010) describe cómo en Chicago en el año 1999, varios psicoanalistas, dirigidos por Kohut (1999), durante sesiones de psicoterapia, registraban las fluctuaciones que se daban entre el terapeuta y el paciente. Estas fluctuaciones, según el propio Kohut (1999), se debían a las imitaciones de las posturas asumidas por el terapeuta y que el paciente asumía. Podemos decir que estas imitaciones se daban como una correspondencia a espejo. Como explicaremos más adelante, se activan las denominadas neuronas espejo.

Las artes escénicas tienen el poder de activar las neuronas espejo. Las neuronas en espejo son grupos específicos de neuronas que se activan, tanto cuando el individuo realiza una acción, como cuando el individuo observa esa misma acción realizada por otra persona. Es decir, observar una acción provoca de forma inmediata la activación del mismo "programa motor" neuronal en el observador, "programa motor" que estará activo durante la ejecución de la acción: cuando observamos una acción, la rehacemos en nuestro interior. Quizá inhibamos la extensión espacial y temporal de esa acción, pero en nosotros ya ha tenido lugar una activación muscular que ha cambiado nuestro equilibrio interno, y que nos ha enviado una información valiosa acerca de lo que está sucediendo ante nuestros ojos.

Ramachandrán (2012), neurólogo hindú, nos cuenta cómo uno de sus pacientes, que había perdido una de sus manos durante la guerra del golfo, ante determinadas acciones era capaz de sentir su mano ausente, a la que denominan mano fantasma. El paciente al observar cómo Ramachandrán golpeaba o acariciaba la mano de otra persona sentía esas acciones observadas en su propia mano fantasma.

En el escenario ponemos en funcionamiento las neuronas espejo, y éstas son capaces de, sin necesidad de desplazar el cuerpo, activar el programa motor. El paciente es el protagonista de la escena, y el profesional le invita a vivenciar el problema a tratar en la terapia en ese lugar imaginario donde se representa la escena.

En la dramatización existen otros espacios además del escenario. El primero de ellos es un espacio sensorial, donde encontramos un gran número de estímulos. Se trata de la superficie de la epidermis, como superficie sensorial, la superficie personal. Un segundo espacio es el espacio peripersonal, es decir, el que rodea a toda persona. Ambos son espacios que nos hacen individuales, nos aíslan y, al mismo tiempo, ayudan a construirnos.

Existe además un espacio interpersonal, el de las relaciones e intercambios. Falleti nos descubre un espacio nuevo, siempre presente en la representación dramática, pero no visible por las personas que presencian la acción dramática. Lo describe como un espacio que se mantiene acotado, como el peripersonal, pero se diferencia de éste en ser un espacio existente, interno en el ser humano, al que denomina "espacio de acción compartido" (Falleti et al., 2010, pp.16-17).

Es un espacio y un tiempo compartido por espectador y actor. Se crea un mecanismo reflejo de las acciones que realizan los demás. Se activan las neuronas espejo de la misma forma que cuando realizamos una acción concreta. De esta manera el cerebro del espectador, al observar la acción del intérprete artístico, la rehace en su interior y activa su sistema motor. Falleti et al. (2010, pp. 20-21) relata cómo el actor al mismo tiempo, a través de una danza invisible, se aloja en el interior del espectador: el espectador está realizando esta danza junto con el intérprete que está en escena y, de forma conjunta, crean un espacio dinámico compartido de acción que es, al mismo tiempo, una danza o peripecia de intenciones.

Las neuronas espejo fueron descubiertas y localizadas en un área del cerebro de un primate que puede considerarse equiparable al área del lenguaje humana. Se considera que antes de lograr la capacidad de comunicarse de forma lingüística, el ser humano lo hacía mediante gestos. En esta capacidad de comunicación gestual las neuronas espejo son tremendamente útiles, ya que descifran la intención comunicativa de la otra persona y controlan el movimiento de las manos (Rizzolatti, 2006). 
A día de hoy conocemos que al hablar y al escuchar, todas esas áreas del cerebro se activan. Rizzolatti en la década de los noventa, junto a su equipo de la Universidad de Parma, consigue localizar el lugar donde se encuentran las neuronas espejo y su sistema. El estudio lo realiza primero en primates y posteriormente en seres humanos. Tras varios estudios localizan las neuronas espejo, ubicándolas en la corteza frontal inferior, muy cercanas al área del habla. La proximidad y cercanía facilita el estudio sobre la relación existente entre la imitación de sonidos y gestos con el lenguaje. Este equipo de la Universidad de Parma consigue descubrir una zona dónde coincide tanto la precepción como la ejecución de una acción.

Otros estudios científicos han hallado neuronas espejo en las cortezas motora y parietal. Estas neuronas comparten las características básicas, pero tienen funciones diversas. Las neuronas localizadas en la corteza parietal, están implicadas en la interpretación de la intención de los gestos. Tanto al percibir un gesto en otra persona, como en el instante en el que uno mismo ejecuta el gesto, las neuronas espejo se activan. Las neuronas espejo son originariamente descubiertas en el cerebro del macaco, pero existen evidencias que confirman encontrarse en el cerebro humano y cómo intervienen en diversas funciones cognitivas, como la empatía o la interpretación de acciones. Y también son asociadas a la función del lenguaje. Las áreas neurales en las que se han encontrado evidencias dentro del cerebro humano son el lóbulo parietal inferior y el pars opercularis (Área 44 de Broca). También en la ínsula, cíngulo anterior y giro temporal superior. Estudios con pacientes, con afectación de la comunicación social, no poseen una activación normal de las neuronas espejo (Enticott et al., 2012).

Schranz (2010) detalla cómo el lenguaje se basa en el sistema de las neuronas espejo y en cómo promueven la imitación. El lenguaje es connatural al ser humano. Pero esta capacidad ha de activarse y desarrollarse. Si a esa capacidad innata le sumamos la adquisición mediante la práctica y la imitación obtendremos una característica que nos define como seres humanos.

Distintas líneas de investigación muestran la importancia que pueden tener las neuronas espejo en el desarrollo motor y del lenguaje (Martín, 2018). La práctica escénica y el juego dramático estimulan el uso de las neuronas espejo, mostrando las posibilidades de una intervención diferente, no invasiva, que podría ser eficaz ante problemas o dificultades tanto físicas, como psicológicas o emocionales. El desarrollo de la conciencia corporal abre una puerta a alternativas para mejorar el estado psicomotor, emocional y social. Sería conveniente profundizar en su estudio, y considerar la posibilidad de la inclusión del juego dramático como recurso terapéutico en los programas de Necesidades Educativas Especiales.

\section{Conclusiones}

Las actividades teatrales repercuten en el entorno y tienen un impacto emocional tanto sobre los participantes como sobre el público. Nos ofrece un espejo en el que examinarnos y nos permite profundizar en la comprensión de nuestras conductas y motivaciones humanas. Aunque el arte dramático y el teatro son actividades profesionales, las personas utilizan técnicas dramáticas y expresiones teatrales en escenarios y situaciones de la vida real.

Participar en actividades de arte dramático y utilizar técnicas de interpretación en la comunicación del día a día puede aumentar la confianza en uno mismo. La naturaleza social del arte dramático y el teatro cimenta la cooperación y la colaboración. Acudir al teatro o formar parte de una producción teatral puede mejorar la concentración y la memoria. Realizar actividades teatrales en una comunidad forja una empatía individual y colectiva al hacer florecer una sensibilidad estética y un compromiso ciudadano.

En un sentido práctico, el arte dramático fomenta la creatividad cotidiana, haciendo que las personas se sientan más vivas, sanas y conectadas con el mundo. La empatía inherente a todo el proceso nos hace estar más abiertos a otras personas y a nuevas experiencias. Conforme dejamos a un lado la incredulidad y nos dejamos atrapar por el mundo de lo imaginario, nos volvemos menos defensivos. Existe una experiencia integral, en la que mente y cuerpo se sienten bien.

Las cuestiones planteadas en la investigación precisan de un acercamiento a la construcción colectiva. No sólo debemos pensar en formar actores, dramaturgos, escenógrafos, bailarines, técnicos, coreógrafos, compositores, intérpretes, diseñadores, cantantes, programadores, productores, directores, también debemos formar espectadores, que sepan apreciar todos estos oficios. Así está escrito en los programas de Educación Artística de todos los países con el concepto de "educación y apreciación artística”, formar para crear y también para apreciar y valorar el arte (González, 2014, 2018). El problema no sólo está en no ser coherente con lo que se dice hacer y defender, en la práctica la Educación Artística se reduce a lo extraescolar durante la educación básica, sino, y aún es más simple, no se cree de forma efectiva en poder hacerlo. Posiblemente cambiar esta actitud sea una utopía, pero las sociedades que no sueñan, permanecen dormidas.

\section{Referencias bibliográficas}

Bamford, A. (2014). "Artes y emociones que potencian la creatividad". Informe Fundación Botín 2014. Santander: Fundación Botín.

Brook, P. (2002). La puerta abierta: Reflexiones sobre la interpretación y el teatro. Barcelona: Alba editorial.

Catterall, J. (2002). Research on drama and theater in education. En R. Deasy (Ed.) Critical links: learning in the arts and student academic and social development. Arts Education Partnership.

Cruciani, F. (1995). Sulla scienza di Stanislavskij, en Registi pedagoghi e comunità teatrali nel Novecento. Roma: Editori \& Associati.

Damasio, A. (2011). El error de Descartes: La emoción, la razón y el cerebro humano. Barcelona: Destino. 
Damasio, A. (2018). El extraño orden de las cosas. Barcelona: Destino.

Dickinson, R., et al. (2006). Improve your Primary School through drama. Gran Bretaña: David Fulton Publishers.

Enticott, P. et al. (2012). Mirror neuron activity associated with social impairments but not age in autism spectrum disorder. In: Biological Psychiatry, 71, pp. 427-433.

Falleti, C., et al., (2010). Diálogos entre teatro y neurociencias. Bilbao: Artezblai.

Gardner, H. (1983). Frames of Mind: The Theory of Multiple Intelligences. Nueva York, EUA: Basic Books.

González, J. (2014). Inteligencia Emocional y Procesos de Creación. México: Caligrama y UG.

González, J. (2014). Arte y Cognición. México: Fontamara.

González, J. (2018). Desarrollo y Evolución de la Creatividad. México: Tirant Lo Blanch.

Karakelle, S. (2009). Enhancing fluent and flexible thinking through the creative drama process. Thinking Skills and Creativity, 4(2), pp.124-129.

Koestler, A (1964). The Act of Creation. London: Hutchinson and Co.

Kohut, H. (1999). La restauración del si-mismo. México: Paidós.

Luna, J. (2008). Complejidad en Educación. Valencia: Nau Llibres

Mallika, H. (2000). Drama's Ways of Learning. In: Research in Drama Education, 5 (1), pp. 45-62.

Martín, L. (2018). El poder terapéutico de la dramatización: estimulación de las neuronas espejos implicadas en el lenguaje a través de emoción. En: Arteterapia, 13, pp. 85-102.

Mercer, N. (2002). Words and minds: How we use language to think together. Nueva York: Routledge.

Motos, T. (2005). Expresión total y educación emocional. Recrearte. Disponible en: http://www.iacat.com/1Cientifica/tomas.

Motos, T. y Navarro, A. (2003). El papel de la dramatización en el currículum. En: Articles, 29, pp.10-28.

Navarro, M. R. (2009). Dramatización y educación emocional. Libro de Resúmenes. III Congreso Internacional de Inteligencia Emocional. España: Fundación Marcelino Botín.

Navarro, M.R. (2007). Drama, Creatividad y Aprendizaje Vivencial: algunas aportaciones del drama a la educación emocional. En: Cuestiones Pedagógicas, 18, pp. 161-172.

Neelands, J. (2004). Miracles are happening: beyond the rhetoric of transformation in the Western traditions of drama education. In: Research in Drama Education, 9 (1), pp. 47-56.

Prendiville, F. y Toye, N. (2007). Social and Emotional Aspects of Education. London: Sage Publications.

Ramachandran, V.; Oberman, L. (2006). Broken mirrors: a theory of autism. Sci Am; 295: pp. 39-45. 4

Rizzolatti, G. (2006). Las neuronas en espejo: los mecanismos de la empatía emocional. Barcelona: Paidós.

Sæbø, A. B. (2009). International Drama and Education Association. Noruega: Universitetet i Stavanger.

Schranz, J. (2010). Hablemos de ampollas. En: Falleti, et, al. (2010). Diálogos entre teatro y neurociencias. Bilbao: Artezblai.

Sofía, G. (2010). Sobre intenciones y resonancias. La relación actor-espectador entre teatro y neurociencias. En Falleti, C., et al. Diálogos entre teatro y neurociencias. Bilbao: Artezblai.

Sofía, G. (2015). Las acrobacias del espectador. Bilbao: Artezblai y Paso de Gato.

Van Zweden, A.; Bosma, P. y Ladan, V. (2014). Artes y emociones que potencian la creatividad. Informe Fundación Botín. Santander: Fundación Botín.

Vygotsky, L. S. (1990). La imaginación y el arte en la infancia. Barcelona: Akal.

Vygotsky, L. S. (1930-2004). Imagination and creativity in childhood. In: Journal of Russian and East European Psychology, 42, pp. 4-84

Vygotsky, L. S. (2005). Psicología del arte. México: Fontamara.

Wandell, B., et, al. (2009). Training in the Arts, Reading, and Brain Imaging. I

n Gazzaniga, M. (ed.). Learning, Arts, and the Brain The Dana Consortium Report on Arts and Cognition; Ed. (51-60). Nueva York: Dana Foundation Press. 